\title{
COMMUNICATION
}

\section{The effect of solvent in direct arylation polycondensation of substituted thiophenes}

Cite this: DOI: $10.1039 /$ xoxxooooox

\author{
Junpei Kuwabara, Kohtaro Yamazaki, Takuya Yamagata, Wataru Tsuchida, Takaki \\ Kanbara*
}

Received ooth January 2012,

Accepted ooth January 2012

DOI: $10.1039 /$ xoxxooooox

www.rsc.org/

In the direct arylation polycondensation of thiophene derivatives, toluene was found to be a suitable solvent for electron-deficient thiophenes, whereas dimethylacetamide (DMAc) was suitable for electron-rich thiophenes.

Polycondensation via dehydrohalogenative cross-coupling reactions, so-called direct arylation, ${ }^{1}$ has recently been recognized as an efficient synthetic protocol for the production of $\pi$-conjugated polymers. $^{2-10}$ As opposed to conventional polycondensation reactions carried out via cross coupling, this protocol has advantages with respect to decreasing the number of reaction steps for monomer preparation and reducing undesired waste from organometallic monomers. ${ }^{11}$ The reduced amount of waste leads to high-purity polymers because of reducing potential inpurity, ${ }^{10 \mathrm{~d}}$ and the highly pure polymer shows high performance in organic field-effect transistors and organic photovoltaics. ${ }^{9}$ However, direct arylation polycondensation is being further developed as a reliable synthetic method for $\pi$-conjugated polymer materials because its application range is still limited in comparison to those of conventional methods. ${ }^{11}$ Therefore, fundamental research regarding direct arylation polycondensation is required to produce a large variety of $\pi$-conjugated polymers with high molecular weights and purities. Notably, the discovery of efficient catalytic systems and their optimization play important roles in metal-catalysed polycondensation reactions. In the first report regarding direct arylation polycondensation, $\mathrm{Pd}(\mathrm{OAc})_{2}$ with a large amount of tetrabutylammonium bromide in dimethylformamide (DMF) was used for synthesis of poly(3-alkylthiophene-2,5-diyl). ${ }^{3}$ However, this catalytic system only afforded low-molecular-weight polymers $\left(M_{\mathrm{n}}\right.$ = 3100). Takita, Ozawa, and co-workers reported that the Herrmann catalyst with $\mathrm{P}\left(\mathrm{C}_{6} \mathrm{H}_{4}-o-\mathrm{NMe}_{2}\right)_{3}$ in THF promoted efficient direct arylation polycondensation, affording poly(3-hexylthiophene-2,5diyl) with a high molecular weight $\left(M_{\mathrm{n}}=32600\right)$ in excellent yield. ${ }^{4}$ The catalytic system was further developed ${ }^{5}$ and applied in the preparation of organic photovoltaics materials. ${ }^{6}$ Our group examined direct arylation polycondensation using $\mathrm{Pd}(\mathrm{OAc})_{2}$ without a phosphine ligand in DMAc. ${ }^{8,9}$ The polycondensation reaction of 3,4ethylenedioxythiophene (EDOT) with 2,7-dibromo-9,9dioctylfluorene under the utilized reaction conditions afforded the corresponding polymer with a high molecular weight $\left(M_{\mathrm{n}}=39400\right)$ in $89 \%$ yield ${ }^{8 \mathrm{~d}}$ However, under the same conditions, the reaction of 5-(2-ethylhexyl)-thieno-[3,4-c]pyrrole-4,6-dione (TPD) did not afford a polymeric product (Scheme S1). In contrast, the direct arylation polycondensation of TPD derivatives was successfully demonstrated by Ozawa ${ }^{5}$ and Leclerc ${ }^{7}$ et al. using THF or toluene as solvents. These observations prompted us to assess the effect of solvent in direct arylation polycondensation reactions; we envisioned that the optimal solvents and catalytic systems would be influenced by the chemical nature of the thiophene monomers. As a proof of concept, we first focused on toluene as a solvent for the polycondensation of TPD, and the polycondensation of various thiophene monomers bearing electron-donating or electronwithdrawing substituents was demonstrated under two types of conditions, namely the newly established toluene-based conditions and the reported DMAc-based conditions. Herein, we report the relationship between the reaction conditions and the nature of the thiophene monomers, which allowed for the preparation of a variety of thiophene-based conjugated polymers via direct arylation polycondensation.

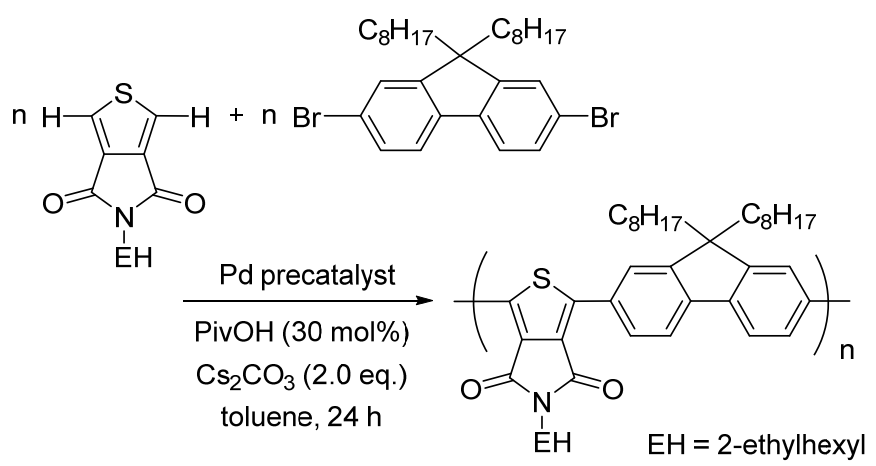

Scheme 1 Direct arylation polycondensation in toluene.

The reaction of TPD with 2,7-dibromo-9,9-dioctylfluorene in toluene was conducted under the conditions reported by Leclerc and co-workers (Scheme 1). ${ }^{7 \mathrm{a}}$ The reaction was carried out using the Herrmann catalyst with $\mathrm{P}\left(\mathrm{C}_{6} \mathrm{H}_{4}-O-\mathrm{OMe}\right)_{3}$ in the presence of pivalic acid and $\mathrm{Cs}_{2} \mathrm{CO}_{3}$. Because the reaction temperature $\left(120{ }^{\circ} \mathrm{C}\right)$ was higher than the boiling point of toluene, a pressure-tight vessel was 
utilized in the reaction. The reaction afforded poly[(5-(2-ethylhexyl)thieno-[3,4-c]pyrrole-4,6-dione-1,3-diyl)-(9,9-dioctylfluorene-2,7diyl)] (PTPDF) with a molecular weight of 20200 in $78 \%$ yield (Table 1, Entry 1). The use of $\mathrm{PCy}_{3} \cdot \mathrm{HBF}_{4}$ rather than $\mathrm{P}_{6}\left(\mathrm{C}_{6} \mathrm{H}_{4}-\right.$ o$\mathrm{OMe})_{3}$ provided a polymer with a higher molecular weight in a higher yield (Entry 2). The results from Entry 3 and 4 revealed that the Herrmann catalyst was not an essential precatalyst; the reactions with $\mathrm{Pd}_{2}(\mathrm{dba})_{3}$ or $\mathrm{Pd}(\mathrm{OAc})_{2}$ afforded polymers with somewhat higher molecular weights in higher yields. In addition, the combination of $\mathrm{Pd}(\mathrm{OAc})_{2}$ and $\mathrm{PCy}_{3} \cdot \mathrm{HBF}_{4}$ allowed for a decrease in the reaction temperature (to $110^{\circ} \mathrm{C}$ ), which was less than the boiling point of toluene and avoided high reaction pressures (Entry 5). Comparable polymerization results were obtained upon reducing the Pd loading to $2 \mathrm{~mol} \%$ (Entry 6 and 7). The reaction was conducted at $100{ }^{\circ} \mathrm{C}$ under the optimized catalytic conditions for comparison with the reported examples ${ }^{8}$ of direct arylation polycondensation in DMAc at $100{ }^{\circ} \mathrm{C}$. The reaction at $100{ }^{\circ} \mathrm{C}$ afforded a comparable result (Entry 8), whereas the reaction at $80{ }^{\circ} \mathrm{C}$ yielded only oligomeric products (Entry 9). Figure 1 shows the ${ }^{1} \mathrm{H}$ NMR spectrum of PTPDF. Each signal can be assigned to the repeating unit, and the signal of the terminal unit was not observed. The integral ratio of the signals agreed with the assignments and was consistent with the alternating structure of the polymer.

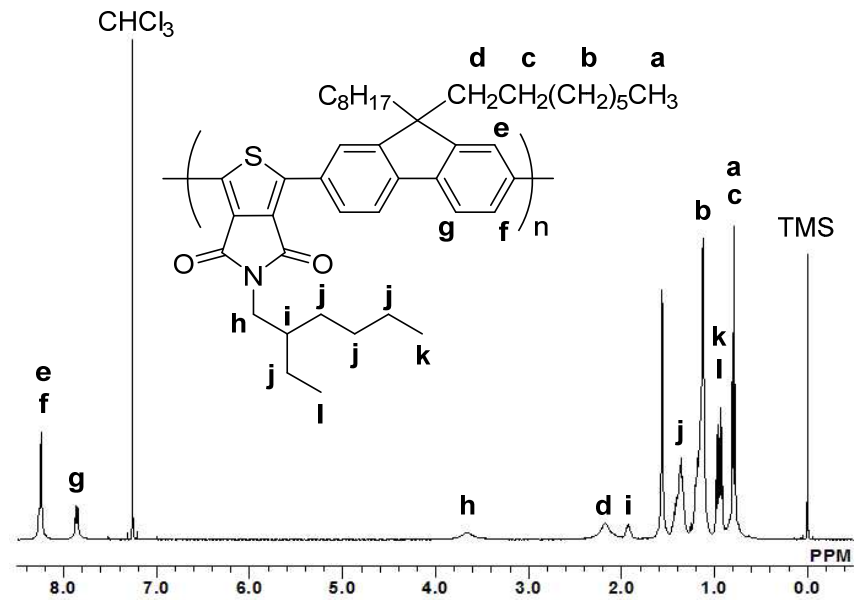

Fig. $1{ }^{1} \mathrm{H}$ NMR spectrum of PTPDF (400 MHz, $\mathrm{CDCl}_{3}$ ).

Table 1 Polycondensation of thieno[3,4-c]pyrrole-4,6-dione with 2,7-dibromo-9,9-dioctylfluorene in toluene

\begin{tabular}{ccccccc}
\hline Entry & Pd precatalyst $(\mathrm{mol} \%)$ & Ligand $^{\mathrm{a}}$ & Temp. $/{ }^{\circ} \mathrm{C}$ & Yield $/ \%^{\mathrm{b}}$ & $M_{\mathrm{n}}{ }^{\mathrm{c}}$ & $M_{\mathrm{w}} / M_{\mathrm{n}}{ }^{\mathrm{c}}$ \\
\hline $1^{\mathrm{d}}$ & Herrmann catalyst (8) & $\left.\mathrm{P}^{\mathrm{C}} \mathrm{C}_{6} \mathrm{H}_{4}-\mathrm{o}-\mathrm{OMe}\right)_{3}$ & 120 & 78 & 20200 & 1.8 \\
$2^{\mathrm{d}}$ & Herrmann catalyst (8) & $\mathrm{PCy}_{3} \cdot \mathrm{HBF}_{4}$ & 120 & 85 & 37000 & 2.4 \\
$3^{\mathrm{d}}$ & $\mathrm{Pd}_{2}(\mathrm{dba})_{3}(8)$ & $\mathrm{PCy}_{3} \cdot \mathrm{HBF}_{4}$ & 120 & 83 & 44600 & 2.5 \\
$4^{\mathrm{d}}$ & $\mathrm{Pd}(\mathrm{OAc})_{2}(8)$ & $\mathrm{PCy}_{3} \cdot \mathrm{HBF}_{4}$ & 120 & 85 & 46400 & 2.6 \\
5 & $\mathrm{Pd}(\mathrm{OAc})_{2}(8)$ & $\mathrm{PCy}_{3} \cdot \mathrm{HBF}_{4}$ & 110 & 96 & 44400 & 2.3 \\
6 & $\mathrm{Pd}(\mathrm{OAc})_{2}(4)$ & $\mathrm{PCy}_{3} \cdot \mathrm{HBF}_{4}$ & 110 & 88 & 44300 & 2.0 \\
7 & $\mathrm{Pd}(\mathrm{OAc})_{2}(2)$ & $\mathrm{PCy}_{3} \cdot \mathrm{HBF}_{4}$ & 110 & 85 & 45500 & 1.9 \\
8 & $\mathrm{Pd}(\mathrm{OAc})_{2}(2)$ & $\mathrm{PCy}_{3} \cdot \mathrm{HBF}_{4}$ & 100 & 93 & 46300 & 1.9 \\
9 & $\mathrm{Pd}(\mathrm{OAc})_{2}(2)$ & $\mathrm{PCy}_{3} \cdot \mathrm{HBF}_{4}$ & 80 & 0 & -
\end{tabular}

${ }^{\mathrm{a}}$ Equimolar amount of the phosphine ligand to a Pd center was added. ${ }^{\mathrm{b}}$ The products were obtained by reprecipitation from $\mathrm{CHCl}_{3} / \mathrm{CH}_{3} \mathrm{OH}$. Estimated by GPC calibrated on polystyrene standards. ${ }^{\mathrm{d}}$ Average values of duplicated runs.

The optimization of the reaction conditions revealed that direct arylation polycondensation of TPD in toluene afforded the corresponding polymer with a high molecular weight in good yield. The reaction of TPD in DMAc did not afford a polymeric product (Scheme S1), although DMAc promoted several direct arylation polycondensation reactions of thiophene derivatives such as 2,3- dimethylthiophene and EDOT. ${ }^{8 \mathrm{~b}-\mathrm{f}}$ Therefore, thiophenes with substituents at the 3 and 4 positions were investigated in the direct arylation polycondensation reaction under the two types of conditions (Scheme 2). Table 2 summarizes the results of the reactions carried out using the DMAc system (Condition A) and the toluene system (Condition B).

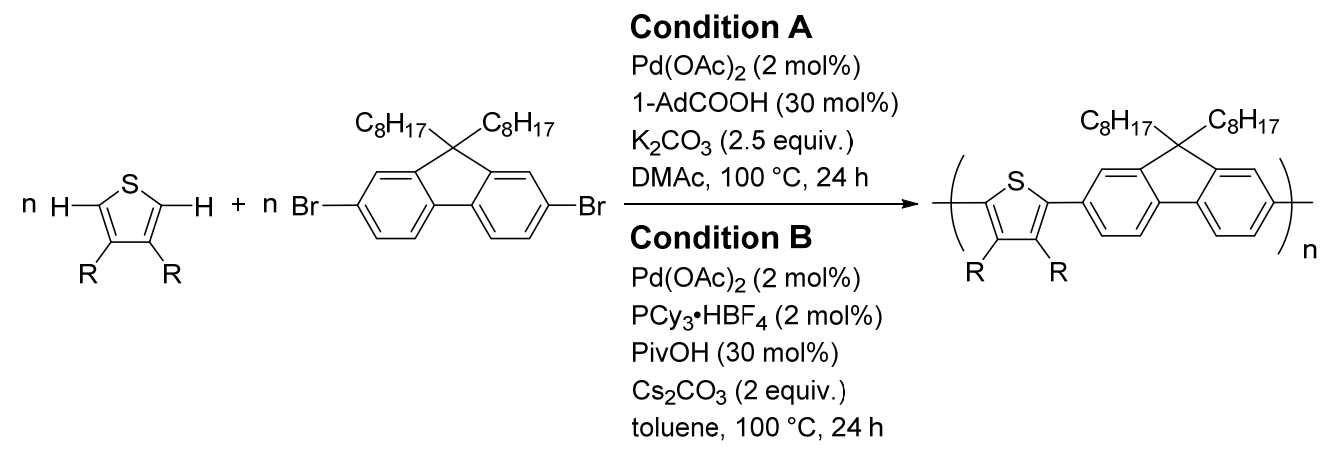

Scheme 2 Direct arylation polycondensation of thiophene derivatives under conditions A and B. 
Table 2 Direct arylation polycondensation of thiophene monomers with various substituents under Conditions A and Condition B

\begin{tabular}{|c|c|c|c|c|c|c|c|}
\hline \multirow{2}{*}{ Entry } & \multirow{2}{*}{ Monomer } & \multicolumn{3}{|c|}{ Condition $\mathrm{A}^{\mathrm{a}}$} & \multicolumn{3}{|c|}{ Condition $\mathrm{B}^{\mathrm{b}}$} \\
\hline & & Yield $/ \%^{c}$ & $M_{\mathrm{n}}^{\mathrm{d}}$ & $M_{\mathrm{w}} / M_{\mathrm{n}}{ }^{\mathrm{d}}$ & Yield / $\%^{\mathrm{c}}$ & $M_{\mathrm{n}}{ }^{\mathrm{d}}$ & $M_{\mathrm{w}} / M_{\mathrm{n}}{ }^{\mathrm{d}}$ \\
\hline $1^{\mathrm{e}}$ & & $87^{\mathrm{f}}$ & $42700^{f}$ & $2.7^{\mathrm{f}}$ & 0 & - & - \\
\hline 2 & & 98 & 11300 & 1.8 & 0 & - & - \\
\hline 3 & & 79 & 13700 & 2.4 & 0 & - & - \\
\hline $4^{g}$ & & 72 & 7000 & 2.3 & $55^{\mathrm{h}}$ & 8300 & 4.7 \\
\hline 5 & & 0 & - & - & 93 & 46300 & 1.9 \\
\hline $6^{\mathrm{e}}$ & & 0 & - & - & $54^{\mathrm{h}}$ & $\begin{array}{c}76000 \\
\left(32500^{\mathrm{i}}\right)\end{array}$ & $\begin{array}{c}3.3 \\
\left(5.9^{\mathrm{i}}\right)\end{array}$ \\
\hline
\end{tabular}

${ }^{\mathrm{a}} \mathrm{Pd}(\mathrm{OAc})_{2}$ (2 mol\%), 1-Adamantanecarboxylic acid (1-AdCOOH, $\left.30 \mathrm{~mol} \%\right), \mathrm{K}_{2} \mathrm{CO}_{3}\left(2.5\right.$ equiv.), DMAc, $100{ }^{\circ} \mathrm{C}, 24 \mathrm{~h} .{ }^{\mathrm{b}} \mathrm{Pd}(\mathrm{OAc})_{2}(2$ $\mathrm{mol} \%$ ), $\mathrm{PCy}_{3} \cdot \mathrm{HBF}_{4}(2 \mathrm{~mol} \%)$, Pivalic acid ( $\left.\mathrm{PivOH}, 30 \mathrm{~mol} \%\right), \mathrm{Cs}_{2} \mathrm{CO}_{3}$ (2 equiv.), toluene, $100{ }^{\circ} \mathrm{C}, 24 \mathrm{~h} .{ }^{\mathrm{c}}$ The yields of the $\mathrm{CHCl}_{3}$-soluble and $\mathrm{CH}_{3} \mathrm{OH}$-insoluble fraction. ${ }^{\mathrm{d}}$ Estimated by $\mathrm{GPC}$ calibrated on polystyrene standards with $\mathrm{CHCl}_{3}$ as eluent at $40{ }^{\circ} \mathrm{C}$. ${ }^{\mathrm{e}} \mathrm{Reaction}$ time is $6 \mathrm{~h}$. ${ }^{\mathrm{f}}$ Reference $8 \mathrm{~d} .{ }^{\mathrm{g}}$ Reaction time is $3 \mathrm{~h} .{ }^{\mathrm{h}} \mathrm{CHCl}_{3}$-insoluble fraction was also formed. ${ }^{\mathrm{i}}$ Estimated by GPC with $o$-dichlorobenzene as eluent at $140{ }^{\circ} \mathrm{C}$.

The reaction of EDOT under Condition A afforded the corresponding polymer in a good yield (Table 2, Entry 1), ${ }^{8 \mathrm{~d}}$ whereas the reaction under Condition $\mathrm{B}$ afforded no polymeric product. In the reactions with 3,4-dioctyloxythiophene and 3,4dimethylthiophene ${ }^{8 \mathrm{~b}}$ the reaction under Condition A only afforded the corresponding polymers (Entry 2 and 3). The reaction of 3,4dichlorothiophene afforded the polymer under Conditions A and B (Entry 4). A low yield (55\%) under Condition B was caused by formation of a $\mathrm{CHCl}_{3}$-insoluble fraction, owing to the low solubility of a high-molecular-weight component. High temperature NMR spectroscopy of the polymers revealed that the structure of the $\mathrm{CHCl}_{3}$-insoluble fraction was essentially the same as that of the soluble fraction (Figure S9). On the other hand, similar to the reaction of TPD (Entry 5), the reaction of 3,4dicyanothiophene yielded a polymer under Condition B (Entry 6). The low yield $(54 \%)$ was due to the formation of a $\mathrm{CHCl}_{3}$ insoluble fraction. The molecular weight of the $\mathrm{CHCl}_{3}$-soluble fraction (76000) was overestimated by the GPC measurement at $40{ }^{\circ} \mathrm{C}$ presumably due to aggregation; high temperature GPC measurement showed molecular weight of 32500 . On the basis of these results, it is clear that the optimal reaction conditions strongly depended on the structure of the thiophenes. In particular, thiophenes with electron-donating substituents reacted better under Condition A, while thiophenes with electron-withdrawing substituents reacted more suitably under Condition B (Table S2). These insights are valuable for the development of direct arylation polycondensation reactions because the optimal reaction conditions can be rapidly estimated on the basis of the structures of the monomers.

DMAc is typically used as the solvent in direct arylation reactions of small molecules. ${ }^{1}$ However, the use of toluene was reported in the reaction of thiophenes with electron-withdrawing substituents, such as 2-cyanothiophene and 2-formylthiophene. ${ }^{12}$ In addition, the direct arylation of 3,4-dicyanothiophene was conducted in xylene, and resulted in a good yield. ${ }^{13}$ Recently, Liu et al. reported superior yields of the direct arylation reactions of TPD derivatives in toluene than those conducted in polar solvents such as DMF and NMP. ${ }^{14}$ These results were consistent with the trend observed in this study. The absence or presence of the phosphine ligand as well as solvent were the significant differences between Conditions A and B. To determine if the phosphine ligand considerably affected the polycondensation or not, the reaction of TPD under Condition A was conducted following the addition of $\mathrm{PCy}_{3} \cdot \mathrm{HBF}_{4}$ (Scheme S2). Because the reaction afforded no polymeric product, the phosphine ligand did not contribute to the large difference observed owing to the varying conditions. The reactions in 1,4-dioxane were conducted to investigate the effect of solvent because 1,4-dioxane has similar polarity and bolting point to toluene (Scheme S3). The reaction of TPD in 1,4-dioxane instead of toluene afforded no polymeric product although the other conditions were same as Condition B. This result shows that low polarity of toluene is not a dominant factor for smooth polymerization of TPD under Condition B. In addition, a reaction of EDOT in 1,4-dioxane afforded only oligomeric products (Scheme S3). A rate-determining step in direct arylation is known to depend on a substrate. ${ }^{15}$ The electronic nature of the substrate may change the rate-determining step leading to affect the suitable reaction conditions. Mechanistic studies are currently in progress to clearly establish the dominant factor.

In summary, this research facilitated the synthesis of highmolecular-weight polymers by direct arylation polycondensation in toluene, which possesses a high solubilizing ability toward $\pi$ conjugated polymers, high boiling point, and generality. The established conditions are suitable for thiophene monomers with 
electron-withdrawing substituents. In contrast, thiophene monomers with electron-donating substituents reacted more favourably in DMAc. These insights are valuable for development of direct arylation polycondensation reactions because the optimal reaction conditions can be rapidly estimated on the basis of the structures of the monomers. Because the relationship between the thiophene structure and reaction conditions should be applicable to wide range of direct arylation reactions, including coupling reactions of small molecules, the fundamental findings described here may provide essential insights regarding direct arylation reactions in general.

\section{Acknowledgements}

This work was supported by Industrial Technology Research Grant Program in 2011 from New Energy and Industrial Technology Development Organization (NEDO) of Japan, and partly supported by Grant-in-Aid for Young Scientists (B) (25810070), Challenging Exploratory Research (25620094) and Scientific Research (B) (25288052). The authors thank to the Chemical Analysis Center of University of Tsukuba for measurements of NMR spectroscopy.

\section{Experimental Part}

Synthesis of PTPDF (Table 1, Entry 8). A mixture of $\mathrm{Pd}(\mathrm{OAc})_{2}$ $(1.1 \mathrm{mg}, 0.0050 \mathrm{mmol}), \mathrm{PCy}_{3} \cdot \mathrm{HBF}_{4}(1.8 \mathrm{mg}, 0.0050 \mathrm{mmol})$, pivalic acid $(8.6 \mu \mathrm{L}, 0.075 \mathrm{mmol}), \mathrm{Cs}_{2} \mathrm{CO}_{3}(163 \mathrm{mg}, 0.50 \mathrm{mmol})$, 2,7-dibromo-9,9-dioctylfluorene (137 mg, $0.25 \mathrm{mmol}), \mathrm{N}$-(2ethylhexyl)thieno[3,4-c]pyrrole-4,6-dione $(66 \mathrm{mg}, 0.25 \mathrm{mmol})$ was stirred in anhydrous toluene $(1.25 \mathrm{~mL})$ for $24 \mathrm{~h}$ at $100{ }^{\circ} \mathrm{C}$ under nitrogen atmosphere. After cooling to room temperature, the mixture was poured into an aqueous solution of ethylenediaminetetraacetic acid disodium salt $(\mathrm{pH}=8)$. The suspension was stirred overnight at room temperature. The precipitate was separated by filtration and washed with $0.1 \mathrm{M} \mathrm{HCl}$ solution, distilled water, $\mathrm{CH}_{3} \mathrm{OH}$, and hexane. The precipitate was dissolved in $\mathrm{CHCl}_{3}$ and the solution was filtered through a plug of Celite to remove insoluble material. A reprecipitation from $\mathrm{CHCl}_{3} / \mathrm{CH}_{3} \mathrm{OH}$ gave PTPDF as yellow solid in $93 \%$ yield. $M_{\mathrm{n}}=46$ $300, M_{\mathrm{w}} / M_{\mathrm{n}}=1.90 .{ }^{1} \mathrm{H}$ NMR $\left(400 \mathrm{MHz}, \mathrm{CDCl}_{3}\right): \delta 8.24$ (overlapped, 4H), $7.86(\mathrm{~d}, J=8.0 \mathrm{~Hz}, 2 \mathrm{H}), 3.66(\mathrm{br}, 2 \mathrm{H}), 2.17$ (br, $4 \mathrm{H}), 1.93(\mathrm{~m}, 1 \mathrm{H}), 1.35-1.45$ (br, 8H), 1.12-1.18 (br, 20H), 0.97 (t, $J=7.2 \mathrm{~Hz}, 3 \mathrm{H}$ ), 0.95 (t, $J=6.8 \mathrm{~Hz}, 3 \mathrm{H}$ ), 0.79 (overlapped, $10 \mathrm{H}$ ). ${ }^{13} \mathrm{C}\left\{{ }^{1} \mathrm{H}\right\}$ NMR $\left(100 \mathrm{MHz}, \mathrm{CDCl}_{3}\right): \delta 163.3,152.4,145.2,142.2$, $130.5,130.2,127.5,122.9,120.6,55.8,42.6,40.1,38.3,31.8,30.6$, $30.0,29.2,29.2,28.5,23.9,23.1,22.6,14.1,14.1,10.5$ (One signal of the alkyl group was overlapped).

\section{Notes and references}

Tsukuba Research Center for Interdisciplinary Materials Science (TIMS), Graduate School of Pure and Applied Sciences, University of Tsukuba, 1-11 Tennodai, Tsukuba 305-8573, Japan

$\dagger$ Electronic Supplementary Information (ESI) available: Experimental procedure, NMR spectra. See DOI: 10.1039/c000000x/

1 (a) T. Satoh and M. Miura, Chem. Lett., 2007, 36, 200; (b) L. Ackermann, R. Vicente and A. R. Kapdi, Angew. Chem., Int. Ed., 2009, 48, 9792; (c) B. Liégault, D. Lapointe, L. Caron, A. Vlassova and K. Fagnou, J. Org. Chem., 2009, 74, 1826; (d) D. Lapointe and K. Fagnou, Chem. Lett., 2010, 39, 1118; (e) R. Rossi,
F. Bellina, M. Lessi and C. Manzini, Adv. Synth. Catal., 2014, 356, 17.

2 For reviews of direct arylation polycondensation, see: (a) $\mathrm{S}$. Kowalski, S. Allard, K. Zilberberg, T. Riedl and U. Scherf, Prog. Polym. Sci., 2013, 38, 1805; (b) L. G. Mercier and M. Leclerc, Acc. Chem. Res. 2013, 46, 1597; (c) P. P. Khlyabich, B. Burkhart, A. E. Rudenko and B. C. Thompson, Polymer, 2013, 54, 5267; (d) K. Okamoto, J. Zhang, J. B. Housekeeper, S. R. Marder and C. K. Luscombe, Macromolecules, 2013, 46, 8059; (e) A. E. Rudenko and B. C. Thompson, J. Polym. Sci., Part A: Polym. Chem., 2014, 52, DOI: 10.1002/pola.27279; (f) J. Kuwabara and T. Kanbara $J$. Synth. Org. Chem., Jpn., 2014, 72, 1271.

3 M. Sévignon, J. Papillon, E. Schulz and M. Lemaire, Tetrahedron Lett., 1999, 40, 5873.

4 Q. Wang, R. Takita, Y. Kikuzaki and F. Ozawa, J. Am. Chem. Soc., 2010, 132, 11420.

5 (a) M. Wakioka, Y. Kitano and F. Ozawa, Macromolecules, 2013, 46, 370. (b) M. Wakioka, M. Ichihara, Y. Kitano and F. Ozawa, Macromolecules, 2014, 47, 626.

6 (a) P. Berrouard, A. Najari, A. Pron, D. Gendron, P.-O. Morin, J.-R. Pouliot, J. Veilleux and M. Leclerc, Angew. Chem., Int. Ed., 2012, 51, 2068; (b) J. Jo, A. Pron, P. Berrouard, W. L. Leong, J. D. Yuen, J. S. Moon, M. Leclerc and A. J. Heeger, Adv. Energy Mater., 2012, 2, 1397; (c) D. H. Wang, A. Pron, M. Leclerc and A. J. Heeger, Adv. Funct. Mater., 2013, 23, 1297.

7 (a) S. Beaupré, A. Pron, S. H. Drouin, A. Najari, L. G. Mercier, A. Robitaille and M. Leclerc, Macromolecules, 2012, 45, 6906; (b) J.R. Pouliot, L. G. Mercier, S. Caron and M. Leclerc, Macromol. Chem. Phys., 2013, 214, 453.

8 (a) W. Lu, J. Kuwabara and T. Kanbara, Macromolecules, 2011, 44, 1252; (b) Y. Fujinami, J. Kuwabara, W. Lu, H. Hayashi and T. Kanbara, ACS Macro Lett., 2012, 1, 67; (c) W. Lu, J. Kuwabara and T. Kanbara, Polym. Chem., 2012, 3, 3217; (d) K. Yamazaki, J. Kuwabara and T. Kanbara, Macromol. Rapid Commun., 2012, 34, 69; (e) J. Kuwabara, Y. Nohara, S. J. Choi, Y. Fujinami, W. Lu, K. Yoshimura, J. Oguma, K. Suenobu and T. Kanbara, Polym. Chem., 2013, 4, 947; (f) S. J. Choi, J. Kuwabara and T. Kanbara, ACS Sustainable Chem. Eng., 2013, 1, 878; (g) W. Lu, J. Kuwabara, and T. Kanbara, Macromol. Rapid Commun., 2013, 34, 1151; (h) M. Kuramochi, J. Kuwabara, W. Lu and T. Kanbara, Macromolecules, 2014, 47, 7378.

9 J. Kuwabara, T. Yasuda, S. J. Choi, W. Lu, K. Yamazaki, S. Kagaya, L. Han and T. Kanbara, Adv. Funct. Mater., 2014, 24, 3226.

10 (a) S. Kowalski, S. Allard and U. Scherf, ACS Macro Lett., 2012, 1, 465; (b) A. E. Rudenko, C. A. Wiley, S. M. Stone, J. F. Tannaci and B. C. Thompson, J. Polym. Sci. Part A: Polym. Chem., 2012, 50, 3691; (c) S.-W. Chang, H. Waters, J. Kettle, Z.-R. Kuo, C-H. Li, C.-Y. Yu and M. Horie, Macromol. Rapid Commun., 2012, 33, 1927; (d) L. A. Estrada, J. J. Deininger, G. D. Kamenov and J. R. Reynolds, ACS Macro Lett., 2013, 2, 869; (e) K. Nakabayashi and H. Mori, Chem. Lett., 2013, 42, 717; (f) X. Zhang, Y. Gao, S. Li, X. Shi, Y. Geng and F. Wang, J. Polym. Sci. Part A: Polym. Chem., 2014, 52, 2367; (g) X. Wang and M. Wang, Polym. Chem., 2014, 5, 5784. 
11 Reviews of polycondensation via cross-coupling reaction. (a) $\mathrm{T}$. Yamamoto, Macromol. Rapid Commun., 2002, 23, 583; (b) J. Roncali, Macromol. Rapid Commun., 2007, 28, 1761; (c) J. Sakamoto, M. Rehahn, G. Wegner and A. D. Schlüter, Macromol. Rapid Commun., 2009, 30, 653; (d) B. Carsten, F. He, H. J. Son, T. Xu and L. Yu, Chem. Rev., 2011, 111, 1493; (e) K. Okamoto and C. K. Luscombe, Polym. Chem., 2011, 2, 2424; (f) T. Yokozawa, Y. Nanashima and Y. Ohta, ACS Macro Lett., 2012, 1, 862; (g) T. Koizumi and T. Kanbara, in Organometallic Reactions and Polymerization, ed. K. Osakada, Springer, Heiderberg, Lecture Notes in Chemistry, 2014, vol. 85, ch. 8, pp. 271-301.

12 D. J. Schipper and K. Fagnou, Chem. Mater., 2011, 23, 1594.

13 A. Yokooji, T. Satoh, M. Miura and M. Nomura, Tetrahedorn Lett., 2004, 60, 6575.

14 S.-Y. Chang, P.-H. Lin and C.-Y. Liu, RSC Adv., 2014, 4, 35868.

15 (a) M. Wakioka, Y. Nakamura, Y. Hihara, F. Ozawa and S. Sakaki, Organometallics, 2013, 32, 4423; (b) M. Wakioka, Y. Nakamura, Y. Hihara, F. Ozawa and S. Sakaki, Organometallics, 2014, 33, 6247. 